\title{
Stromverdrängung im Ankerstreufeld
}

\section{Doctoral Thesis}

Author(s):

Wanger, Willi

Publication date:

1928

Permanent link:

https://doi.org/10.3929/ethz-a-000271023

Rights / license:

In Copyright - Non-Commercial Use Permitted 


\title{
Stromverdrängung im Ankerstreufeld
}

\author{
Von der \\ Eidgenössischen Technischen Hochschule \\ in Zürich \\ zur Erlangung der
}

Würde eines Doktors der technischen Wissenschaften genehmigte

No. 528 Promotionsarbeit

vorgelegt von

\section{Willi Wanger}

aus $\mathrm{Z}$ uirich

Referent: Herr Prof. Dr. K. Kuhlmann

Korreferent: Herr Prof. Dr. P. Scherrer

Weida i. Thtir. 1928

Druck von Thomas \& Hubert

Spezialdruckerei für Dissertationen 


\section{Die Brauchbarkeit des Kuhlmannschen Apparates.}

Ich möchte noch kurz die Eignung des Kuhlmann schen Apparates für die experimentelle Bestimmung der zusätzlichen Kupferverluste einer vorausberechneten, noch nicht gebauten Maschine diskutieren. Selbstverständlich können mit Hilfe dieses Apparates nur die Ankerkupferverluste der unerregten Maschine ermittelt werden. Meine ausgedehnten experimentellen Untersuchungen haben aber gezeigt, $\mathrm{daB}$ für diesen Betriebszustand bei offenen und halboffenen Nuten die Theorie von Emde, bei geschlossenen Nuten meine Sättigungstheorie recht gute Resultate liefern. Es wird deshalb im allgemeinen nicht nötig sein, für eine neu zu bauende Maschine die Kupferverluste durch Stromverdrängung im Ankerstreufeld im voraus experimentell zu bestimmen. Sollte aber trotzdem einmal eine solche Untersuchung mit Hilfe des Kuhlmannschen Apparates erwünscht sein, so ist zu beachten, daB dieser Apparat nicht die gleichen Sättigungsverhältnisse im Eisen aufweist wie ein wirklicher Anker, selbst wenn die Zähne in beiden Fällen genau die gleiche Form haben. Bei offenen und halboffenen Nuten ist der Einflub der Eisensättigung so gering, daß das Widerstandsverbältnis beim Kuhlman nschen Apparat nur um wenige Prozente von dem beim wirklichen Anker abweicht; bei geschlossenen Nuten ist dagegen die Induktionsverteilung im Eisen und daher nach der Sättigungstheorie auch das Widerstandsverhältnis beim Kuhlmannschen Apparat vollständig anders als beim wirklichen Anker.

\section{Rückblick.}

Für die Stromverdrängung des Ankerleiters im eigenen Streufeld wurde die sog. Sättigungstheorie aufgestellt, d. i. eine Näherungstheorie, die im Gegensatz zur bisher gebräuchlichen Theorie die magnetische Spannung im Eisen berücksichtigt. Mit dem Kuhlmannschen Apparat wurde die Richtigkeit dieser Theorie in bezug auf Stromverteilung und Widerstandsverhältnis für verschiedene Nutformen und Leiteranordnungen experimentell nachgewiesen. Dabei wurde auch gezeigt, daß man den Kupferverlust für verzerrten Strom erhält, indem man den Kupferverlust für jede einzelne Harmonische nach der erwähnten Theorie berechnet und diese Werte addiert. 
Für den wirklichen Anker kann die Stromverdrängung im Ankerstreufeld nach der Sättigungstheorie berechnet werden, sobald das magnetische Feld in den Zähnen und im Ankerrücken bekannt ist. Theoretische Überlegungen haben gezeigt, daB bei offenen und halboffenen Nuten die magnetische Spannung im Eisen gegenüber derjenigen quer durch die Nuten zu vernachlässigen ist, so daß die Sättigungstheorie mit der Theorie von Emde übereinstimmt. Bei geschlossenen Nuten dagegen ist das nach der Sättigungstheorie berechnete Widerstandsverhältnis immer etwas kleiner als das nach der Emdeschen Theorie berechnete, für offene Nuten gültige Widerstandsverhältnis. Der Unterschied beträgt aber in allen praktischen Fällen nur wenige Prozente. - Die Theorie von Rogowski für geschlossene Nuten ist unrichtig.

Bei der Maschine im belasteten Betriebszustand verursacht außer dem Ankerstreufeld auch das Hauptfeld Wirbelströme in den Ankerleitern. Zur Berechnung des totalen Ankerkupferverlustes müßte zunächst die resultierende Stromverteilung im Ankerleiter ermittelt werden. Dafür gibt es aber noch keine Theorie. Falls die vom Hauptfeld induzierten Wirbelströme vernachlässigbar klein sind, so ist das Widerstandsverhältnis des Ankerleiters bei erregter Maschine etwas kleiner als bei unerregter. Der Unterschied beträgt in praktischen Fällen höchstens etwa $15 \%$. 